\title{
Nutrition and sarcopenia of ageing
}

\author{
Satoshi Fujita and Elena Volpi* \\ Department of Medicine, Division of Endocrinology and Diabetes, University of Southern California, \\ 1333 San Pablo Street, BMT-B11, Los Angeles, CA 90033, USA
}

\begin{abstract}
Sarcopenia, the loss of muscle mass and function with ageing, is a multifactorial condition that slowly develops over decades and becomes a significant contributor to disability in the older population. Malnutrition and alterations in the muscle anabolic response to nutritional stimuli have been identified as potentially preventable factors that may significantly contribute to sarcopenia. In the present article we review the most recent findings regarding the role of nutritional factors in the development, prevention and treatment of sarcopenia. Specifically, we focus on the nutritional needs of the elderly; the age-related changes in the response of muscle protein metabolism to feeding and to the endogenous hormones released during feeding; and the role played by the splanchnic tissues in the response of muscle proteins to feeding. Finally, we review the issues relative to the potential use of nutritional therapies, including supplementation, for the prevention and treatment of sarcopenia.
\end{abstract}

\section{Ageing: Sarcopenia: Protein metabolism}

\section{Introduction}

The human lifespan is steadily increasing, and trials to further prolong longevity are currently underway. On the other hand, ageing is also associated with a progressive loss of physical independence, which significantly worsens the quality of life. A fundamental cause of and contributor to disability in older individuals is the involuntary loss of muscle mass, strength, and function (sarcopenia) (Evans, 1995; Lexell, 1995; Roubenoff \& Castaneda, 2001). Sarcopenia increases the risk of falls and vulnerability to injury and, consequently, can lead to functional dependence and disability (Wolfson et al. 1995; Tinetti \& Williams, 1997). A decrease in muscle mass and function can also lead to a reduction in physical activity, which may have possible metabolic effects including decreased bone density, obesity and impaired glucose tolerance (Dutta \& Hadley, 1995; Evans, 1995). It has been shown that a loss of approximately 3-5\% of muscle mass per decade occurs after the age of 30 years, although this decline is higher after the age of 60 years and older (Holloszy, 2000; Melton et al. 2000).

The aetiology of sarcopenia is not clearly understood, but several mechanisms have been proposed, including:

(a) irreversible fibre damage or permanent denervation resulting in a loss of contact between nerve and muscle fibre (Lexell, 1995); (b) mitochondrial DNA deletion mutations subsequent to oxidative damage (Cortopassi et al. 1992);

(c) changes in satellite cell recruitment (Allen \& Rankin, 1990; McCormick \& Thomas, 1992);

(d) altered endocrine function (for example, changes in hormone, growth factor, and/or cytokine release) and/or impaired tissue responsiveness to the hormonal stimuli (Tenover et al. 1988; Kelijman, 1991; Tenover, 1992; Roubenoff, 1993; Roubenoff et al. 1998);

(e) changes in tissue response to nutrients and/or malnutrition (Mosoni et al. 1995; Morley, 1997; Volpi et al. 2000).

It is probable that sarcopenia is a multifactorial problem. Nevertheless, it is important to underscore that any of the aetiological factors that determine muscle loss with ageing will eventually induce an imbalance between muscle protein synthesis and breakdown with a resulting loss of muscle proteins and overall muscle mass. Therefore, the study of muscle protein metabolism is a very useful tool to assess the mechanism(s) that are involved in the development of sarcopenia.

Previous studies had suggested that sarcopenia is due to a reduced basal rate of mixed muscle and myofibrillar protein synthesis (Welle et al. 1993, 1995; Yarasheski et al. 1993; Balagopal et al. 1997; Hasten et al. 2000). However, we have recently reported in the largest cohort of healthy men to date that, despite a decline in muscle mass, basal

* Corresponding author: Dr Elena Volpi, fax +1 323442 2809, email volpi@usc.edu 
muscle protein synthesis and breakdown are not reduced with healthy ageing (Volpi et al. 2001). Since these data were collected in healthy subjects it is not possible to exclude that diseases, which are more prevalent in the ageing population, may influence muscle mass and strength, thus contributing to sarcopenia. Nevertheless, from a clinical perspective it is encouraging that in healthy individuals an age-related reduction of basal protein synthesis could not explain the sarcopenia of ageing, as it would be difficult to target such a fundamental response with an appropriate therapeutic intervention.

In healthy adult subjects, muscle mass is maintained constant by the fine balance between the catabolic periods (i.e. fasting, stress) and the anabolic stimuli (i.e. feeding, muscle contraction). Thus, we can speculate that if we exclude abnormalities in basal muscle protein turnover, which accounts for most of the fasting catabolism, muscle loss with ageing in healthy subjects is probably due to a reduced exposure to the anabolic stimuli and/or alterations in the response to one or more anabolic factors, such as feeding or contraction. In the present review article we will focus on the nutritional aspects of sarcopenia.

\section{Nutritional intake and needs in the elderly}

It has been shown that ageing is associated with a progressive reduction in food intake, which predisposes to energyprotein malnutrition (Morley, 1997). Nationwide studies in the USA have suggested that low dietary energy intake is common among healthy elderly adults (McDowell et al. 1994). A number of factors including neurophysiological (for example, anorexia), psychological (for example, depression), social (for example, loneliness) and physical changes (for example, poor dentition) may determine both a reduction in food intake and changes in food preference with an increased predilection for sweet, protein-poor foods (Morley, 1997).

The protein requirements for elderly individuals have been recently confirmed by the report from the Institute of Medicine to be similar to those of adults 55 years and younger $(0.8 \mathrm{~g} / \mathrm{kg}$ per $\mathrm{d}$; Food and Nutrition Board and Institute of Medicine, 2002). However, there has been some recent speculation (Campbell et al. 1994, 2001) that the protein requirements for older individuals may be higher than that currently recommended (more than $1 \mathrm{~g} / \mathrm{kg}$ per d). Specifically, Campbell et al. (1994) found that elderly subjects had a reduction in $\mathrm{N}$ excretion and midthigh muscle area following a 2 -week isoenergetic diet containing the currently recommended dietary reference intake for protein $(0.8 \mathrm{~g} / \mathrm{kg}$ per d). These data suggest that the dietary reference intake for protein may not be adequate to meet the metabolic requirements of healthy elderly individuals.

Thus, nutritional interventions are appealing potential means for the prevention and treatment of sarcopenia of the elderly due to their easy applicability and safety. However, attempts to improve muscle mass in elderly subjects with protein supplementation have been largely unsuccessful (Fiatarone et al. 1994; Campbell et al. 1995; Welle \& Thornton, 1998). In frail older subjects, Fiatarone et al. (1994) reported an increase in muscle strength associated with resistance exercise, whereas nutritional supplementation alone did not increase either muscle mass or strength. Furthermore, nutritional supplementation added to resistance exercise did not result in an increase in muscle mass, strength, or muscle protein synthesis as compared with exercise alone (Fiatarone et al. 1994; Campbell et al. 1995; Welle \& Thornton, 1998).

There are several possible explanations for these negative results. On the one hand, it is difficult to achieve a true nutritional supplementation, defined as an increase in daily energy and/or protein intake, in older individuals. Fiatarone et al. (1994) reported that the only group in which true supplementation was achieved was the one undergoing both nutritional supplementation and exercise training (i.e. the only group with an increased energy expenditure), whereas the total energy intake did not change in the group assigned to supplementation alone. This means that in the latter group the supplement was in reality a food substitute. Since the supplement composition was not very different from the composition of a regular diet, it is not surprising that in these subjects the supplementation failed to improve muscle mass and strength. Another possibility is that in older subjects the ability to utilise dietary amino acids for muscle protein accretion is reduced, so that a much larger amount of amino-N is needed to increase muscle protein anabolism, thus explaining the apparent increased protein needs of the elderly (Campbell et al. 2001). Our own data support this notion.

\section{Response of muscle proteins to exogenous amino acids in the elderly}

In general, if there is an age-related decline in the ability to utilise exogenous amino acids, this could be due to specific problems of the muscle fibres, such as decreased transmembrane amino acid transport and/or utilisation for protein synthesis. The decline could be due to alterations in the whole-body amino acid turnover that reduce the availability of exogenous amino acids for the muscle tissue, thus limiting the availability of substrate for net protein synthesis, or to alterations in the endogenous hormonal response and/or in the response of muscle to the hormonal stimuli that normally follow a meal.

Previous studies have demonstrated that amino acid availability is critical in the regulation of muscle protein metabolism (Rennie et al. 1982; Biolo et al. 1997) Specifically, hyperaminoacidaemia acutely stimulates muscle protein synthesis by increasing the amino acid transport into muscle cells (Biolo et al. 1997). Based on these data, we initially investigated whether an age-associated decline in the ability of skeletal muscle to efficiently transport exogenous amino acids was responsible for a reduction in the response of muscle protein synthesis to an amino acid load. Thus, we measured amino acid transport and muscle protein synthesis and breakdown in healthy elderly volunteers in the post-absorptive state and during the intravenous infusion of an amino acid mixture (Volpi et al. 1998). For the measurement of the muscle protein metabolic parameters we used stable-isotope methodologies including both the traditional measurement of muscle protein fractional synthesis rate with the precursor-product method (Toffolo 
et al. 1993), and a newer isotope-dilution method for the measurement of leg and muscle amino acid kinetics (Biolo et al. 1995). The latter method allowed us to measure not only the rate at which amino acids are utilised for protein synthesis and breakdown, but also the rate at which the different amino acids are transported into and out of muscle cells.

We found that in older subjects the parenteral amino acid infusion significantly increased amino acid delivery to the leg, amino acid transport, and muscle protein synthesis (Volpi et al. 1998). Since protein breakdown did not change during amino acid infusion, a positive net balance of amino acids across the muscle was achieved, indicating muscle protein deposition. The effects of amino acid infusion observed in older subjects were not different from those seen in younger individuals. From these data we concluded that, although muscle mass decreases in the elderly, muscle protein anabolism can nonetheless be directly stimulated by increased amino acid availability. Nevertheless, it is important to consider that these experiments were performed using the parenteral route for amino acid administration in order to directly assess muscle responsiveness to a specific amino acid load. Thus, we had eliminated a number of variables that physiologically play an important role in the overall response of muscle to a nutritional stimulus.

\section{Splanchnic tissues and muscle protein metabolism in the elderly}

It is essential to consider that amino acids are physiologically introduced in the body through the gut, usually in the form of proteins. Thus, digestion and absorption are important limiting factors. Recent studies have shown that the type of protein ingested may affect the protein anabolic response at the whole-body level. Boirie et al. (1997a) found that the speed of protein digestion and amino acid absorption from the gut has a major effect on whole-body protein anabolism. In young subjects, proteins that are digested slowly (for example, casein) appear to induce an overall better anabolic response at the whole-body level as compared with proteins that are digested more rapidly (for example, whey protein) (Boirie et al. 1997a; Dangin et al. 2001). In older individuals, however, it appears that proteins that are rapidly digested and absorbed induce a better anabolic response as compared with the 'slower' proteins (Dangin et al. 2002). Arnal et al. $(1999,2000)$ found that the protein-feeding pattern is also important for optimal $\mathrm{N}$ retention. Specifically, they found that in older women protein pulse feeding induces a better $\mathrm{N}$ retention as compared with continuous feeding (Arnal et al. 1999), whereas this is not true in younger individuals (Arnal et al. 2000). Overall, from these data it appears that in order for amino acids to maximally stimulate protein anabolism in older individuals they need to rapidly flood the system, whereas this is not the case in younger individuals. Thus, these data suggest that age somewhat affects the modalities by which amino acids are disposed for protein synthesis.

Another important hurdle that dietary amino acids need to overcome in order for them to reach the systemic circulation and, eventually, the muscle tissue are the splanchnic tissues. The dietary amino acids have to necessarily pass through the splanchnic tissues (for example, gut, liver, etc) before they are released into the systemic circulation and made available for the peripheral tissues. It is well known that in young individuals the splanchnic tissues use a significant proportion of the dietary amino acids for their own metabolism (Matthews et al. 1993). Thus, only a proportion of the ingested amino acids will eventually be available for the peripheral tissues, especially for muscle. There is some evidence that the importance of the splanchnic tissue in the regulation of whole-body protein turnover increases with age (Young, 1990). Thus, if the splanchnic tissues utilise more amino acids in the elderly, the flow and availability of dietary amino acids for the peripheral tissues, including muscle, would be reduced. This hypothesis was corroborated by the observation of Boirie et al. (1997b) that the first-pass splanchnic extraction of leucine increases with age. An increased first-pass splanchnic extraction of amino acids could reduce the availability of the extracted amino acids for the peripheral tissues. Therefore, the response of muscle protein anabolism to a given dose of amino acids would be blunted in the elderly. To test this hypothesis we compared the response of muscle protein metabolism to the oral administration of mixed amino acids in young and older subjects using stable-isotope methodologies to measure the parameters of muscle protein metabolism (Volpi et al. 1999). We found that despite a higher phenylalanine first-pass splanchnic extraction in the elderly, the delivery of phenylalanine to the leg increased to the same extent both in the young and in the elderly. Additionally, phenylalanine transport into the muscle, utilisation for protein synthesis, mixed muscle protein fractional synthesis rate and net balance increased significantly and similarly both in the young and in the elderly. Thus, from these data we concluded that although the splanchnic first-pass extraction of oral amino acids increases with age, this does not prevent the dietary amino acids from reaching the systemic circulation and stimulating net muscle protein anabolism in the elderly as in the young. It is interesting to note that an increased first-pass splanchnic extraction of a dietary amino acid is an index of its increased utilisation (for synthesis and/or oxidation) in the splanchnic tissues.

During amino acid intake the overall amino acid output from the splanchnic tissues to the systemic circulation is similar in the young and in the elderly despite a higher firstpass splanchnic extraction. This fact suggests that the higher amino acid first-pass splanchnic extraction in older subjects is more of a reflection of a higher splanchnic turnover rate (increased synthesis and breakdown) rather than an isolated higher splanchnic utilisation rate for synthesis and oxidation. In other words, we believe that the higher uptake of labelled dietary amino acids in older subjects is counterbalanced by a higher release of unlabelled amino acids deriving from splanchnic protein breakdown. However, further investigations are necessary to investigate this hypothesis.

A subsequent comparison of the results obtained in older subjects with oral amino acid administration (Volpi et al. 1999) with those obtained using a similar dose of amino acids delivered intravenously (Volpi et al. 1998) demonstrated that the response of muscle protein anabolism to either parenteral or oral mixed amino acids was similar. 
This indicates that increased amino acid availability stimulates muscle protein synthesis independent of the administration mode (Rasmussen et al. 2002).

\section{Endogenous hormonal response and muscle amino acid utilisation}

Our data supporting the notion that amino acids acutely stimulate muscle protein anabolism in older subjects as well as in younger individuals (Volpi et al. 1998, 1999) are apparently at odds with previous studies. In these studies nutritional supplementation had failed to improve either acute muscle protein synthesis (Welle \& Thornton, 1998) or muscle mass over a prolonged period of treatment (Fiatarone et al. 1994; Campbell et al. 1995). These differences were even more striking if we consider that in our studies (Volpi et al. 1998, 1999) basal muscle protein turnover was not different between age groups, suggesting that the gains obtained with the acute supplementation would not be lost during the muscle catabolic periods. However, this was not necessarily the case, since different combinations of nutrients were used. We used a balanced mixture of amino acids alone (Volpi et al. 1998, 1999), whereas all the other studies used a mixture of protein, fat and carbohydrate (Fiatarone et al. 1994; Campbell et al. 1995; Welle \& Thornton, 1998). When amino acids are given alone, in the absence of other nutrients, the endogenous hormonal response is significantly blunted. Consequently, if there were an alteration in the response of muscle to the hormones that are normally secreted following a mixed meal it would have not been detected with the use of amino acids alone or proteins as test meals.

Based on these considerations, we tested whether the response of muscle protein synthesis, breakdown and net balance to the ingestion of a mixture of amino acids and glucose was reduced in healthy older subjects as compared with younger controls (Volpi et al. 2000). We found that although phenylalanine net balance became positive in both age groups, indicating net anabolism, the increase was significantly blunted in the elderly (Volpi et al. 2000). The difference in muscle protein anabolism between the elderly and young was due to the complete unresponsiveness of muscle protein synthesis to the amino acid-glucose stimulus in the elderly, whereas the synthesis rate increased twofold in the young. At the same time, muscle protein breakdown decreased by the same extent in both age groups. Thus, the net balance shift to a positive value during amino acid-glucose intake in the elderly was entirely due to a reduction in protein breakdown. These findings were somewhat surprising considering that we had previously shown that amino acids alone stimulate net muscle protein anabolism in the elderly as in the young by increasing protein synthesis in the absence of effects on breakdown (Volpi et al. 1998, 1999). Additionally, both young and older subjects were glucose tolerant and had a similar glucose uptake and production as assessed with labelled glucose during the experiment. One of the previous studies was performed by administering the same dose of amino acids given in the present experiment to comparable groups of young and older volunteers (Volpi et al. 1999). This gave us the opportunity to compare the general effects of amino acids with glucose and those of amino acids alone on net muscle protein anabolism in the young and elderly (Fig. 1). Whereas glucose significantly increased the positive effect of amino acids in the young, in the elderly phenylalanine net balance was slightly but not significantly higher during amino acids with glucose when compared with amino acids alone. Overall, these results suggest that while in young adults the addition of glucose to an amino acid mixture augments the protein anabolic effect of amino acids and promotes muscle protein deposition, such a combination in the elderly does not add a real benefit. In fact, the addition of carbohydrate reduces muscle protein turnover by both preventing the stimulatory effect of amino acids on protein synthesis and inhibiting protein breakdown, thereby reducing muscle tissue remodelling.

Our data are consistent with recent findings in old rats indicating that muscle protein synthesis is blunted during balanced feeding containing both protein and carbohydrates (Mosoni et al. 1995). Because both the commercial supplements and the high-protein diets previously tested in older adults contained carbohydrate (Fiatarone et al. 1994; Campbell et al. 1995; Welle \& Thornton, 1998), this alone might provide a sufficient explanation for the ineffectiveness of these earlier interventions.

We are currently investigating the hypothesis that the changes in the behaviour of muscle protein synthesis observed during amino acid-glucose supplementation is due to a relative resistance of muscle proteins to insulin. This is because the main differences between the amino acid meal and the mixed amino acid-glucose meals were the total energy content, which was double in the amino acid-glucose meal, and the endogenous insulin response, which was much higher with the amino acid-glucose meal. The excess energy seems an unlikely candidate for the negative effect of the mixed meal on muscle protein synthesis because the synthetic process is energy consuming (Welle \& Nair,

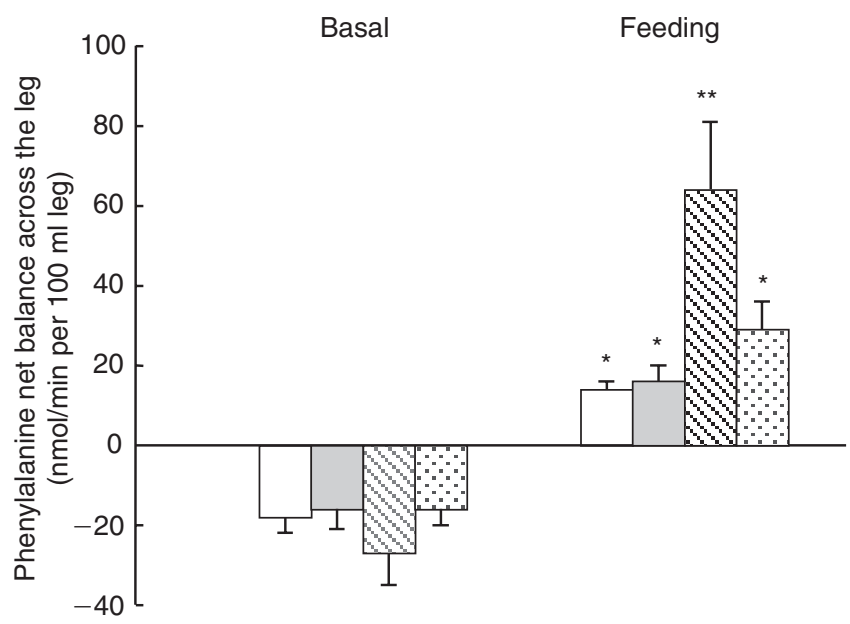

Fig. 1. Net muscle protein balance in young ( $\square$, 8. $(\square, \square$ ) subjects in response to a chemically defined meal containing either $40 \mathrm{~g}$ balanced amino acids only $(\square, \square$ ) (same pattern found in meat proteins; Reeds et al. 1994), or the same amount of balanced amino acids plus $40 \mathrm{~g}$ glucose $(\square, \because$ ). Values are means, with standard errors represented by vertical bars. ${ }^{\star} P<0.05$, values $v$. basal. ${ }^{* *} P<0.05$, values $v$. others. 
1990). Thus, we would expect that if energy had any effect on protein synthesis, it should play a positive, rather than a negative role. On the other hand, insulin resistance is a potential candidate because insulin can stimulate muscle protein synthesis, when amino acid availability is adequate, and reduce protein breakdown (Wolfe \& Volpi, 2000). Additionally, ageing is associated with reduced insulin sensitivity. Thus, future investigations on the potential development of an age-related insulin resistance of muscle proteins are warranted.

\section{Nutritional interventions for sarcopenia: the concept of anabolic efficiency}

We have previously mentioned that older subjects who were given supplements in the absence of increases in physical activity decreased their dietary intake accordingly, so that their total daily energy intake remained unchanged (Fiatarone et al. 1994). This suggests that nutritional supplements for the elderly should be better considered as dietary substitutes. Consequently, if the nutrient content of the supplement is little different from that of the normal diet, it is probable that the supplementation will be ineffective. Hence, a nutritional supplement for the prevention or treatment of sarcopenia should only contain the nutrients that are absolutely necessary for the stimulation of muscle protein anabolism, in order to achieve the highest anabolic efficiency per energy unit.

Considering the data from Fiatarone et al. (1994) suggesting that older subjects reduce their food intake when supplemented, we put forward the hypothesis that a supplement for the elderly should be highly efficient to effectively stimulate muscle growth. Our own data indicated that a balanced mixture of amino acids could effectively stimulate muscle protein synthesis and anabolism in older subjects (Volpi et al. 1998, 1999). However, data obtained in younger subjects also suggested that essential amino acids are mostly responsible for the amino acid stimulation of muscle protein synthesis (Smith et al. 1992, 1998), whereas non-essential amino acids are apparently ineffective even at very high doses (Smith et al. 1998). Non-essential amino acids comprise a significant proportion of dietary proteins, including the high-quality proteins (i.e. whey, egg) that are typically used to supplement protein-poor diets. Thus, we hypothesised that if non-essential amino acids are not necessary for the stimulation of muscle anabolism in older individuals, even high-quality proteins could be inadequate for an effective treatment of sarcopenia since they contain a significant amount of energy in the form of non-essential amino acids. In this case, the elimination of non-essential amino acids should maximise the anabolic efficiency of a supplement for the elderly by decreasing the total energy content while maintaining the stimulatory effect on muscle protein synthesis.

We determined the relative role of essential and nonessential amino acids on the stimulation of muscle protein anabolism in older adults. We did this by comparing the response of muscle protein metabolism to either $18 \mathrm{~g}$ essential amino acids (about $0 \cdot 20 \mathrm{~g} / \mathrm{kg}$ ) or $40 \mathrm{~g}$ balanced amino acids (18 g essential amino acids plus $22 \mathrm{~g}$ non-essential amino acids; about $0.5 \mathrm{~g} / \mathrm{kg}$ ) given orally after an overnight fast (Volpi et al. 2003). We found that both supplements exerted a similar anabolic effect by stimulating muscle protein synthesis with no effect on muscle protein breakdown. Using the phenylalanine net balance data, and assuming that phenylalanine represents about $4 \%$ of amino acids that constitute muscle proteins, we estimated that on average each subject gained approximately $3 \mathrm{~g}$ protein per leg in response to either supplement during the acute experimental period.

It is important to consider that whereas the essential amino acid content and composition of both supplements was identical, the balanced amino acid supplement delivered more than twice as much energy and amino- $\mathrm{N}$ as the essential amino acid supplement. This finding reinforces the notion that the anabolic effect of amino acids on muscle proteins is primarily due to the essential amino acids, especially the branched-chain amino acids ( $\mathrm{Li} \&$ Jefferson, 1978; Garlick \& Grant, 1988); leucine in particular (Buse \& Reid, 1975; Anthony et al. 2000, 2002). This effect is possibly through the stimulation of mRNA translation via an increased formation of the eukaryotic initiation factor $4 \mathrm{~F}$ complex, the activation of ribosomal protein S6, and some other mechanisms that have not yet been elucidated (Anthony et al. 2000, 2002). Overall, we found that the acute anabolic efficiency of the essential amino acid supplement (expressed as the pre-post difference in phenylalanine net balance across leg per energy unit delivered by the supplement) was double that of the efficiency of the balanced amino acid supplement. In addition, the acute anabolic efficiency of the essential amino acid supplement was more than double that of the balanced amino acid supplement containing glucose (Fig. 2).

Since non-essential amino acids do not appear to be necessary for the stimulation of muscle protein anabolism

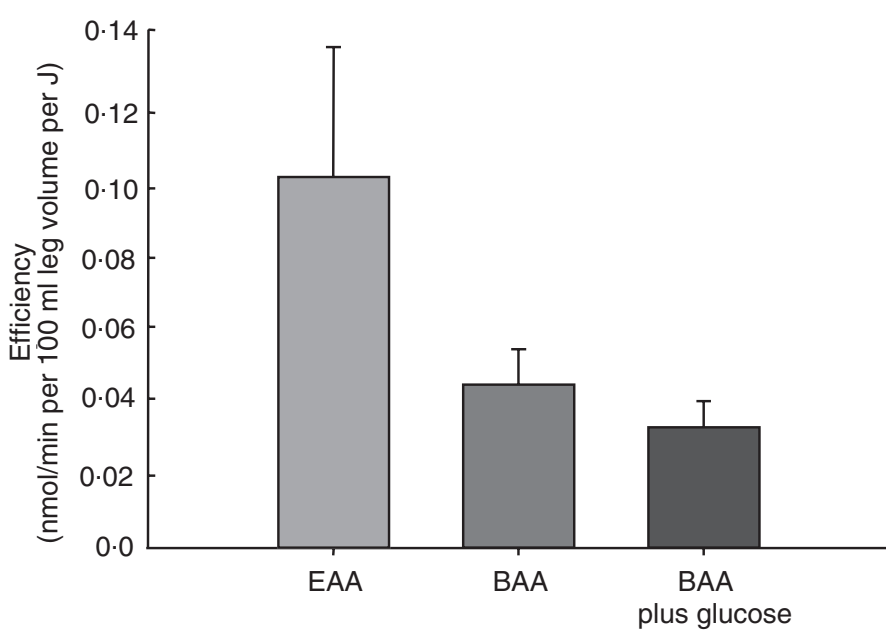

Fig. 2. Anabolic efficiency of $18 \mathrm{~g}$ essential amino acids (EAA), $40 \mathrm{~g}$ balanced amino acids (BAA, containing the same amount and proportion of essential amino acids of EAA), and BAA plus $40 \mathrm{~g}$ glucose. The anabolic efficiency was calculated dividing the pre-post difference in phenylalanine net balance across the leg by energy delivered by the supplement. Values are means, with standard errors represented by vertical bars. 
in older individuals, high-quality proteins may still be inadequate for a dose-effective treatment of sarcopenia, given the excessive amount of energy they provide in the form of non-essential amino acids. The elimination of any source of energy that is inefficient for protein anabolism, including non-essential amino acids, should not decrease the final anabolic effect of the essential amino acid supplement for the elderly, while significantly decreasing its total energy content. On the other hand, essential amino acid supplements are expensive and may be poorly palatable, which may significantly reduce compliance over the long term. For this reason, although their anabolic efficiency may be lower than that of essential amino acids, high-quality proteins may still be a useful alternative to essential amino acids as they are inexpensive, readily available both as common foods (for example, egg white) or nutritional supplements (for example, whey protein) and more palatable. However, since the data on the efficiency of nutritional supplements for the elderly have been obtained with acute experiments, long-term randomised clinical trials are necessary to ascertain the efficacy and cost-effectiveness of different types of nutritional supplements for the reduction of muscle loss with ageing.

\section{Conclusions}

The data currently available underscore the importance of nutrition and nutritional factors in the development, prevention and treatment of sarcopenia. In particular, protein malnutrition and changes in the responsiveness of muscle proteins to nutrients and hormones may play a significant role in the loss of muscle with age. Nutritional strategies may therefore be very useful to reduce muscle loss with age and stimulate muscle growth in individuals currently affected by sarcopenia. The composition of meals and supplements and the administration modality appear to be critical factors for the successful use of nutrition as a means for the treatment of sarcopenia.

Future research should focus, on the one hand, on the mechanisms responsible for the changes in the response of muscle proteins to insulin. On the other hand, long-term clinical trials are necessary to test the efficacy of specific nutrients, such as amino acids or 'slow' and 'fast' proteins, as tools for the prevention and the treatment of sarcopenia. In this context, it will also be important to ascertain the importance of the food administration modality, such as the timing of supplementation in relation to the main meals. Finally, it will also be important to assess whether the combination of specific nutritional interventions with other types of interventions, such as hormonal replacement (for example, testosterone or growth hormone) and exercise training may improve the muscle protein anabolic response in older individuals with sarcopenia.

\section{Acknowledgements}

The present review was supported in part by NIH grant no. R01 AG18311, and by the Brookdale Foundation.

\section{References}

Allen RE \& Rankin LL (1990) Regulation of satellite cells during skeletal muscle growth and development. Proceedings of the Society for Experimental Biology and Medicine 194, 81-86.

Anthony JC, Reiter AK, Anthony TG, Crozier SJ, Lang CH, MacLean DA, Kimball SR \& Jefferson LS (2002) Orally administered leucine enhances protein synthesis in skeletal muscle of diabetic rats in the absence of increases in 4E-BP1 or S6K1 phosphorylation. Diabetes 51, 928-936.

Anthony JC, Yoshizawa F, Anthony TG, Vary TC, Jefferson LS \& Kimball SR (2000) Leucine stimulates translation initiation in skeletal muscle of postabsorptive rats via a rapamycin-sensitive pathway. Journal of Nutrition 130, 2413-2419.

Arnal MA, Mosoni L, Boirie Y, Houlier ML, Morin L, Verdier E, Ritz P, Antoine JM, Prugnaud J, Beaufrere B \& Mirand PP (1999) Protein pulse feeding improves protein retention in elderly women. American Journal of Clinical Nutrition 69, 1202-1208.

Arnal MA, Mosoni L, Boirie Y, Houlier ML, Morin L, Verdier E, Ritz P, Antoine JM, Prugnaud J, Beaufrere B \& Mirand PP (2000) Protein feeding pattern does not affect protein retention in young women. Journal of Nutrition 130, 1700-1704.

Balagopal P, Rooyackers OE, Adey DB, Ades PA \& Nair KS (1997) Effects of aging on in vivo synthesis of skeletal muscle myosin heavy-chain and sarcoplasmic protein in humans. American Journal of Physiology 273, E790-E800.

Biolo G, Fleming RY, Maggi SP \& Wolfe RR (1995) Transmembrane transport and intracellular kinetics of amino acids in human skeletal muscle. American Journal of Physiology 268, E75-E84.

Biolo G, Tipton KD, Klein S \& Wolfe RR (1997) An abundant supply of amino acids enhances the metabolic effect of exercise on muscle protein. American Journal of Physiology 273, E122-E129.

Boirie Y, Dangin M, Gachon P, Vasson MP, Maubois JL \& Beaufrere B (1997a) Slow and fast dietary proteins differently modulate postprandial protein accretion. Proceedings of the National Academy of Sciences USA 94, 14930-14935.

Boirie Y, Gachon P \& Beaufrere B (1997b) Splanchnic and wholebody leucine kinetics in young and elderly men. American Journal of Clinical Nutrition 65, 489-495.

Buse MG \& Reid SS (1975) Leucine: a possible regulator of protein turnover in muscle. Journal of Clinical Investigation 56, 1250-1261.

Campbell WW, Crim MC, Dallal GE, Young VR \& Evans WJ (1994) Increased protein requirements in elderly people: new data and retrospective reassessments. American Journal of Clinical Nutrition 60, 501-509.

Campbell WW, Crim MC, Young VR, Joseph LJ \& Evans WJ (1995) Effects of resistance training and dietary protein intake on protein metabolism in older adults. American Journal of Physiology 268, E1143-E1153.

Campbell WW, Trappe TA, Wolfe RR \& Evans WJ (2001) The recommended dietary allowance for protein may not be adequate for older people to maintain skeletal muscle. Journals of Gerontology 56A, M373-M380.

Cortopassi GA, Shibata D, Soong NW \& Arnheim N (1992) A pattern of accumulation of a somatic deletion of mitochondrial DNA in aging human tissues. Proceedings of the National Academy of Sciences USA 89, 7370-7374.

Dangin M, Boirie Y, Garcia-Rodenas C, Gachon P, Fauquant J, Callier P, Ballevre O \& Beaufrere B (2001) The digestion rate of protein is an independent regulating factor of postprandial protein retention. American Journal of Physiology 280, E340E348.

Dangin M, Boirie Y, Guillet C \& Beaufrere B (2002) Influence of the protein digestion rate on protein turnover in young and elderly subjects. Journal of Nutrition 132, 3228S-3233S. 
Dutta C \& Hadley EC (1995) The significance of sarcopenia in old age. Journals of Gerontology 50A, 1-4.

Evans WJ (1995) What is sarcopenia? Journals of Gerontology 50A, 5-8.

Fiatarone MA, O’Neill EF, Ryan ND, Clements KM, Solares GR, Nelson ME, Roberts SB, Kehayias JJ, Lipsitz LA \& Evans WJ (1994) Exercise training and nutritional supplementation for physical frailty in very elderly people. New England Journal of Medicine 330, 1769-1775.

Food and Nutrition Board and Institute of Medicine (2002) Protein and amino acids. In Dietary Reference Intakes for Energy, Carbohydrates, Fiber, Fat, Protein and Amino Acids, pp. 465-608 [Institute of Medicine, editor]. Washington, DC: The National Academies Press.

Garlick PJ \& Grant I (1988) Amino acid infusion increases the sensitivity of muscle protein synthesis in vivo to insulin. Effect of branched-chain amino acids. Biochemical Journal 254, 579-584.

Hasten DL, Pak-Loduca J, Obert KA \& Yarasheski KE (2000) Resistance exercise acutely increases MHC and mixed muscle protein synthesis rates in 78-84 and 23-32 yr olds. American Journal of Physiology 278, E620-E626.

Holloszy JO (2000) The biology of aging. Mayo Clinic Proceedings 75, Suppl., S3-S8

Kelijman M (1991) Age-related alterations of the growth hormone/insulin-like-growth-factor I axis. Journal of the American Geriatrics Society 39, 295-307.

Lexell J (1995) Human aging, muscle mass, and fiber type composition. Journals of Gerontology 50A, 11-16.

Li JB \& Jefferson LS (1978) Influence of amino acid availability on protein turnover in perfused skeletal muscle. Biochimica Biophysica Acta 544, 351-359.

McCormick KM \& Thomas DP (1992) Exercise-induced satellite cell activation in senescent soleus muscle. Journal of Applied Physiology 72, 888-893.

McDowell MA, Briefel RR, Alaimo K, Bischof AM, Caughman CR, Carroll MD, Loria CM \& Johnson CL (1994) Energy and Macronutrient Intakes of Persons Aged 2 Months and Over in the United States: Third National Health and Nutrition Examination Survey, Phase 1, 1988-91. Hyattsville, MD: National Center for Health Statistics.

Matthews DE, Marano MA \& Campbell RG (1993) Splanchnic bed utilization of leucine and phenylalanine in humans. American Journal of Physiology 264, E109-E118.

Melton LJ III, Khosla S, Crowson CS, O'Connor MK, O'Fallon WM \& Riggs BL (2000) Epidemiology of sarcopenia. Journal of the American Geriatrics Society 48, 625-630.

Morley JE (1997) Anorexia of aging: physiologic and pathologic. American Journal of Clinical Nutrition 66, 760-773.

Mosoni L, Valluy MC, Serrurier B, Prugnaud J, Obled C, Guezennec CY \& Mirand PP (1995) Altered response of protein synthesis to nutritional state and endurance training in old rats. American Journal of Physiology 268, E328-E335.

Rasmussen BB, Wolfe RR \& Volpi E (2002) Oral and intravenously administered amino acids produce similar effects on muscle protein synthesis in the elderly. Journal of Nutrition, Health and Aging 6, 358-362.

Reeds PJ, Fjeld CR \& Jahoor F (1994) Do the differences between the amino acid compositions of acute-phase and muscle proteins have a bearing on nitrogen loss in traumatic states? Journal of Nutrition 124, 906-910.

Rennie MJ, Edwards RHT, Halliday D, Matthews DE, Wolman SL \& Millward DJ (1982) Muscle protein synthesis measured by stable isotope techniques in man: the effects of feeding and fasting. Clinical Science 63, 519-523.

Roubenoff R (1993) Hormones, cytokines and body composition: can lessons from illness be applied to aging? Journal of Nutrition 123, Suppl., 469-473.
Roubenoff R \& Castaneda C (2001) Sarcopenia - understanding the dynamics of aging muscle. Journal of the American Medical Association 286, 1230-1231.

Roubenoff R, Rall LC, Veldhuis JD, Kehayias JJ, Rosen C, Nicolson M, Lundgren N \& Reichlin S (1998) The relationship between growth hormone kinetics and sarcopenia in postmenopausal women: the role of fat mass and leptin. Journal of Clinical Endocrinology and Metabolism 83, 1502-1506.

Smith K, Barua JM, Watt PW, Scrimgeour CM \& Rennie MJ (1992) Flooding with $\left[1-{ }^{13} \mathrm{C}\right]$ leucine stimulates human muscle protein incorporation of continuously infused L- $\left[1-{ }^{13} \mathrm{C}\right]$ valine. American Journal of Physiology 262, E372-E376.

Smith K, Reynolds N, Downie S, Patel A \& Rennie MJ (1998) Effects of flooding amino acids on incorporation of labeled amino acids into human muscle protein. American Journal of Physiology 275, E73-E78.

Tenover JS (1992) Effects of testosterone supplementation in the aging male. Journal of Clinical Endocrinology and Metabolism 75, 1092-1098.

Tenover JS, Matsumoto AM, Clifton DK \& Bremner WJ (1988) Age-related alterations in the circadian rhythms of pulsatile luteinizing hormone and testosterone secretion in healthy men. Journal of Gerontology 43, M163-M169.

Tinetti ME \& Williams CS (1997) Falls, injuries due to falls, and the risk of admission to a nursing home. New England Journal of Medicine 337, 1279-1284.

Toffolo G, Foster DM \& Cobelli C (1993) Estimation of protein fractional synthetic rate from tracer data. American Journal of Physiology 264, E128-E135.

Volpi E, Ferrando AA, Yeckel CW, Tipton KD \& Wolfe RR (1998) Exogenous amino acids stimulate net muscle protein synthesis in the elderly. Journal of Clinical Investigation $\mathbf{1 0 1}$ 2000-2007.

Volpi E, Kobayashi H, Sheffield-Moore M, Mittendorfer B \& Wolfe RR (2003) Essential amino acids are primarily responsible for the amino acid stimulation of muscle protein anabolism in healthy elderly adults. American Journal of Clinical Nutrition 78, 250-258.

Volpi E, Mittendorfer B, Rasmussen BB \& Wolfe RR (2000) The response of muscle protein anabolism to combined hyperaminoacidemia and glucose-induced hyperinsulinemia is impaired in the elderly. Journal of Clinical Endocrinology and Metabolism 85, 4481-4490.

Volpi E, Mittendorfer B, Wolf SE \& Wolfe RR (1999) Oral amino acids stimulate muscle protein anabolism in the elderly despite higher first pass splanchnic extraction. American Journal of Physiology 277, E513-E520.

Volpi E, Sheffield-Moore M, Rasmussen BB \& Wolfe RR (2001) Basal muscle amino acid kinetics and protein synthesis in healthy young and older men. Journal of the American Medical Association 286, 1206-1212.

Welle S \& Nair KS (1990) Relationship of resting metabolic rate to body composition and protein turnover. American Journal of Physiology 258, E990-E998.

Welle S, Thornton C, Jozefowicz R \& Statt M (1993) Myofibrillar protein synthesis in young and old men. American Journal of Physiology 264, E693-E698.

Welle S, Thornton C \& Statt M (1995) Myofibrillar protein synthesis in young and old human subjects after three months of resistance training. American Journal of Physiology 268, E422E427.

Welle S \& Thornton CA (1998) High-protein meals do not enhance myofibrillar synthesis after resistance exercise in 62- to 75-yr-old men and women. American Journal of Physiology 274, E677-E683.

Wolfe RR \& Volpi E (2000) Insulin and protein metabolism. In 
The Endocrine Pancreas and Regulation of Metabolism, vol. II, pp. 733-755 [LS Jefferson and AD Cherrington, editors]. New York: Oxford University Press.

Wolfson L, Judge J, Whipple R \& King M (1995) Strength is a major factor in balance, gait, and the occurrence of falls. Journals of Gerontology 50A, 64-67.
Yarasheski KE, Zachwieja JJ \& Bier DM (1993) Acute effects of resistance exercise on muscle protein synthesis rate in young and elderly men and women. American Journal of Physiology 265, E210-E214.

Young VR (1990) Amino acids and proteins in relation to the nutrition of elderly people. Age and Ageing 19, S10-S24. 